\title{
The Pituitary of the African Lungfish Protopterus sp.
}

\author{
T. KERR \\ Department of Zoology, University of Leeds, England \\ AND \\ P. G. W. J. VAN OORDT \\ Zoological Laboratory, State University of Utrecht, The Netherlands
}

Received April 11, 1966

\begin{abstract}
In general structure, the distal lobe closely resembles that of an amphibian, whereas the elaborate intermingling of nervous and intermediate lobes recalls the typical fish condition. In cell types, the majority of the intermediate-lobe cells have the same reactions as in amphibians but there is in addition another cell type which appears to be unique. In the distal lobe there are three types of basophils and two of acidophils, in many respects resembling the same five cell types found in amphibians. Developmental stages help to explain the structure of the neuralintermediate complex.
\end{abstract}

\section{INTRODUCTION}

The general structure of the Protopterus gland has been put on a firm foundation by Wingstrand (1956) and some histological details are available in Dawson (1940). However, it has now become possible to give a much closer comparison between its cell types and those of amphibians (see the review by van Oordt, 1963). Little attention too has previously been paid to the intermediate and nervous lobes which in this fish are structurally much more complicated than in tetrapods, as implied by the older name of "infundibular gland" and here the examination of developmental stages has been found useful. Finally, the systeruatic position of the dipnoans, as the closest living relatives to the crossopterygian ancestors of the land animals, gives the pituitary of Protopterus a considerable interest in the reconstruction of a general evolutionary sequence.

\section{MATERIALS AND METHODS}

The material available consisted of fourteen larval and young Protopterus aethiopicus ranging from 3 to $35 \mathrm{~cm}$, some fixed for histology and others merely for gross anatomy, and eleven adults ranging from 65 to $170 \mathrm{~cm}$ in total length; in addition there were two adult $P$. dotloi of 70 and $95 \mathrm{~cm}$, and one $P$. annectens of $20 \mathrm{~cm}$. For histological details only glands fixed in Bouin's fluid or in Bouin-Hollande, with or without the addition of $10 \%$ aqueous mercuric chloride, were used and longitudinal and transverse sections were cut at $4 \mu$ or $7 \mu$. Routine staining was by Aleian Blue-PAS-orange $G$ or Luxol Fast Blue-PASorange $G$ (see. Kerr, 1965) and Herlant's tetrachrome (Herlant, 1960). Additionally sections were stained with aldehyde-fuchsin (AF) according to Halmi (1952) with Lugol's solution as the oxidizing agent, or according to Gabe's (1953) procedire, in which the staining solution is made up in another way and acidified permanganate used as the oxidant. G. T. Gurr dyestuffs were used throughout, apart from the acid alizarine blue of the tetrachrome; stain, for which the original Hoechist dye was available.

The nomenclature of the cell types in the pituitary will no doubt be based eventually upon their functions, but the choice of a conycnient system for destgnating cells which are being described for the first time and whose function. is uncertain is beset by a number of difficultios (see van Oordt, 1965). Names based upon color 
imply the use of a particular technique, so that not only will different color names be equally appropriate for the same cell but also there is no certainty that the same technique will not give different color renderings of the corresponding cell in different animals. The Greek-letter terminology on the other hand has been used in so many different senses by different authors that its use is now precluded. It has appeared simplest therefore to retain the classical terms acidophil and basophil and to subdivide lhem by numbers, on the understanding that these numbers are being used in an uncommitted sense to apply only to the material being described; at the same time several standard techniques have been used in each diagnosis to facilitate comparison with the cell types of other forms.

\section{RESULTS}

The Distal Lobe of $\mathrm{P}$. aethiopicus

In the 3-cm fish the distal lobc, represented by a layer of cells below the hypophysial cavity, is already thicker towards the rear and by $7.5 \mathrm{~cm}$ (Fig. 6) the deepening has become more marked and can be seen to be due to the presence of enlarging acidophils; this difference only gradually disappears as the basophils, especially those of Type 2, become established to produce the more homogeneously shaped lobe of the adult fish (Fig. 2). In the two very large $(170 \mathrm{~cm})$ specimens, a further enlargement of the posterior region, again due to an increase in acidophils, is very marked (Fig. 4). The blood supply to the distal lobe is established early and becomes very rich, as it runs along the connective tissue sheets which divide up the glandular tissue into irregular lobules (Fig. 2). The capillaries entering the distal lobe from the median eminence region are associated with a modified anterior part of this lobe which is here referred to as the terminal zone. Three types of basophils (Fig. 1) and two of acidophils can be distinguished in the adult gland (Table 1).

Basophils, Type 1. These are rounded or oval cells which are distributed in considerable numbers throughout the whole anterior portion of the lobe (where they show a noticeable degree of association with the intrinsic blood vessels) and more scantily all round the periphery, except in the terminal zone; however there is a quite large centro-posterior area in which these cells are lacking (Figs. 1 and 3). Their granules are coarse and somewhat irregular in shape, and react with Alcian Blue and with PAS; they also react with both the aldehyde-fuchsin (AF) of Gabe after acidified permanganate oxidation, and with that of Gomori after Lugol oxidation (see Kerr, 1965) (Fig. 3). In a proportion of the cells, the granules are elumped together so

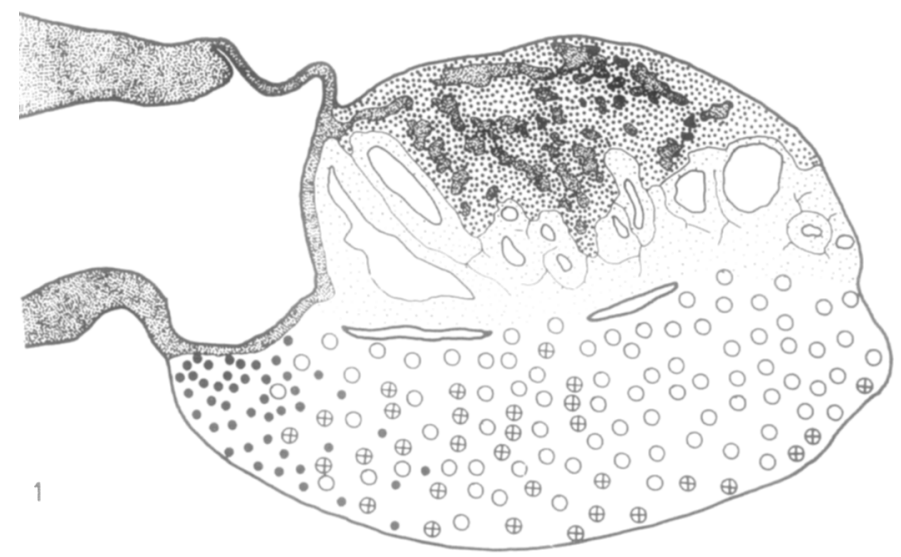

FIG. 1. Diagram of sagittal section of adult gland (135-cm fish) to show mainly the distribution of the three types of basophils in the distal lobe: Type 1, crossed circles; Type 2, open circles; Type 3, small solid circles. Distal lobe, unstippled; hypophysial cavity subdivided and more heavily outlined; intermediate lobe, small open stippling; brain and ependymal tissue, small close stippling; fibrous portion of nervous lobe, heavy stippling. 
TABLE 1

Summary of Statning Reactions in Protopterus aethiopicus

\begin{tabular}{lcccc}
\hline \multicolumn{1}{c}{ Stain } & $\begin{array}{c}\text { Acidophils } \\
\text { Type 1 }\end{array}$ & $\begin{array}{c}\text { Acidophils } \\
\text { Type 2 }\end{array}$ & $\begin{array}{c}\text { Basophilsa } \\
\text { Types 1 \& 2 }\end{array}$ & $\begin{array}{c}\text { Basophils } \\
\text { Type 3 }\end{array}$ \\
\hline PAS & - & $(+)$ & + & + \\
Alcian blue & - & - & + & - \\
Gabe's AF & - & - & + & - \\
Luxol fast blue & + & + & - & - \\
Luxol-PAS-orange G & Light green & Dark green & Purple & Brown red \\
Alcian-PAS-orange G & Yellow orange & Brown orange & Blue & Brown red \\
Herlant & Red & Orange & Blue & Violet \\
Cleveland \& Wolfe & Red & Orange & Blue & Violet \\
\hline
\end{tabular}

${ }^{a}$ A single column has been used for basophils, Types 1 and 2, to emphasize that, when the cells are described in terms of color alone, they appear to be similar; when such other features as shape and granule size are taken into account they can be separated quite clearly.

that the cells are smaller and appear solid; but in general the cells are larger and the granules show separately. This change in the distribution of the granules can be followed through intermediate stages and appears to be due to the production of small vacuoles in the cytoplasm. A further constant feature of these cells is that the cell boundary is very clearly defined by a ring of chromophilic substance (Fig. 5). In the 11-cm fish, the Type-1 basophils have already appeared. Initially they form a fairly well defined central mass; later they appear more anteriorly in the substance of the lobe and posteriorly in small numbers round the periphery, with acidophils becoming numerous posteriorly and laterally (Figs. 7 and 9). In all the stages up to the $35-\mathrm{cm}$ fish the individual basophils are solid in appearance, resembling the more solid form of these cells seen in the adult.

Basophils, Type 2. This type is much more elongated in shape, typically with the nucleus at one end of the cell and with the other end of the cell against a capillary. It is most easily distinguished from the foregoing by the numerous granules, smaller and more homogeneous, and by the lack of the sharp'y defined cell boundary (Fig. 5) . The granu'es are again positive to both Alcian Blue and PAS but they stain more lightly than those of Type 1, and this difference in staining intensity can be emphasized by the use of a stronger stain such as aldehyde-thionine. After Cleveland and Wolfe's or Herlant's tetrachrome they again stain a lighter blue. Types 1 and 2 cannot be separated on a color differenoe after either Alcian Blue-PAS-orange $G$ or PAS-orange $G$ alone, as is usually possible in amphibians; however, Type 2 are positive to Gabe's AF but negative to Gomori's after Lugol. These cells are entirely absent from the younger fish, including those of $35 \mathrm{~cm}$, but in the adult they are more numerous than Type 1; here they occur throughout the lobe up to the terminal zone, and in the centro-posterior region of the lobe, already mentioned, they alone are present among the acidophils.

Basophils, Type 3. These are smaller cells, more rounded in shape and relatively much fewer in number. Their distribution is quite characteristic (Fig. 1). Along with chromophobic cells they predominate in the terminal zone of the lobe where the capillaries enter from the median eminence region; from here they extend in some numbers along the lower surface and in smaller numbers within the substance of approximately the anterior quarter of the distal lobe. (It should be noted that the median eminence in Protoptems is thin and so undifferentiated that it can only be defined by reference to the capillary network. On this basis the region overlaps the distal lobe to a considerable extent so that the terminal zone is dorsal as well as anterior.) The staining reactions of the cells are equally charaeteristic. They are positive to PAS but negative to Alcian Blue, although prolonged 


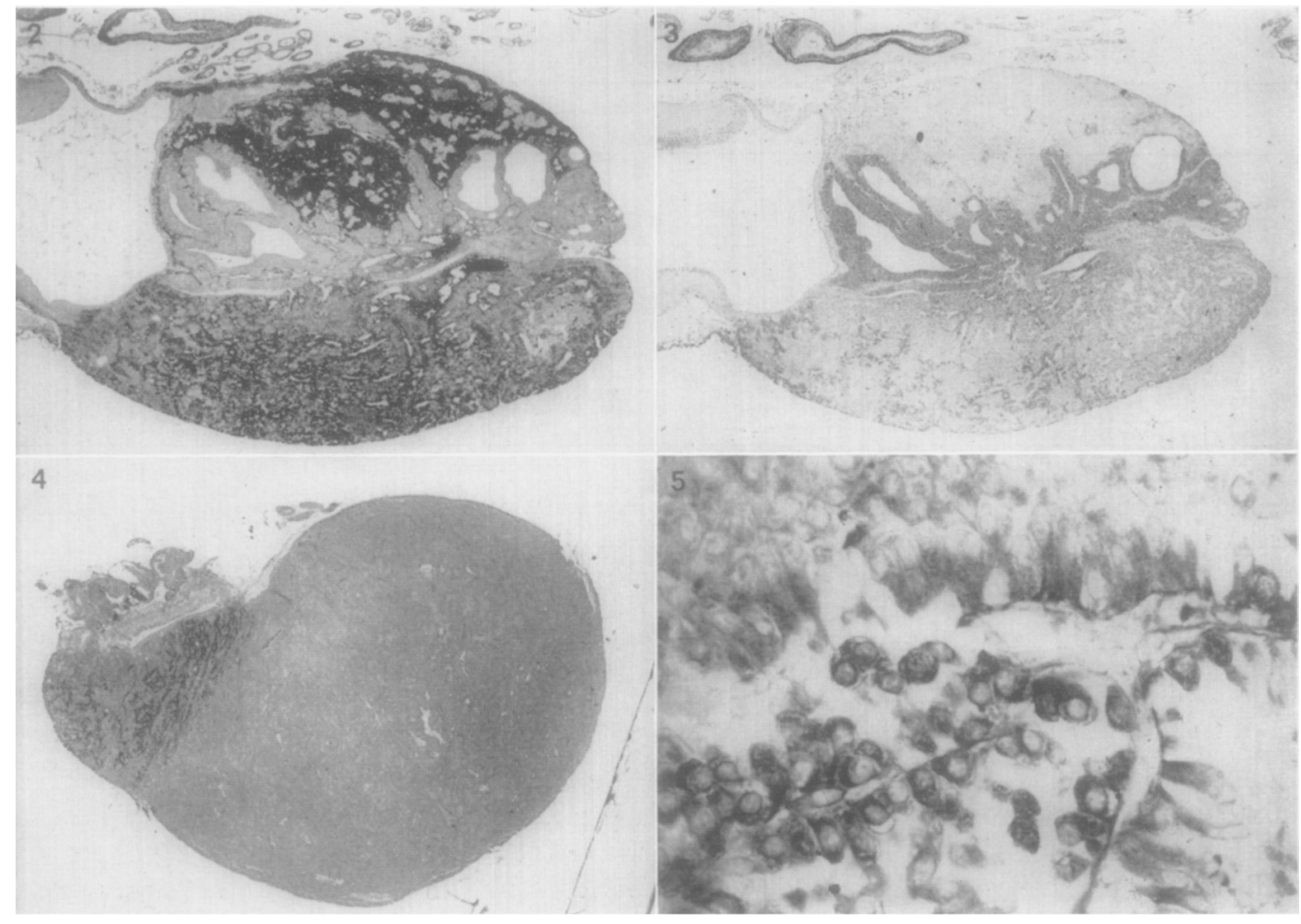

FIg. 2. Longitudinal section of $135-\mathrm{cm} P$. aethiopicus. All three types of basophils stained. Ordinary intermediate cells lightly stained, neurosecretion darkly stained. Alcian Blue--PAS-orange $\mathrm{G} . \times 24$. In all longitudinal sections, the head end is to the left.

FIG. 3. Same as Fig. 2, but stained with Gomoris aldehyde-fuchsin after Lugol oxidation. Types 1 and 3 basophils positive, Type 2 almost negative. Ordinary intermediate cells positive, neurosecretion almost negative; with Gabe's $A F$ after acidified permanganate oxidation, the nervous and intermediate lobes would resemble those of Fig. 2 in a black and white photograph. $\times 24$.

FIg. 4. Longitudinal section of very large $(170 \mathrm{~cm}) P$. aethiopicus to show great posterior enlargement of distal lobe. AF-orange G. $\times 10$.

Fic. 5. Part of distal lobe of 135-cm P. aethiopicus to show two types of basophils. The dark, rounded cells are basophils, type 1 ; the more finely granular, elongated cells are basophils of Type 2 . Alcian Blue-PAS-orange G. $\times 350$.

staining will evoke a weak reaction; they are positive to Gomori's AF after Lugol (Fig. 3), but negative to Gabe's after acidified permanganate. With the tetrachrome or Cleveland and Wolfe techniques they stain a distinctive light violet. These cells are already well established and deeply staining in a 20 -cm fish (Fig. 7) at a stiage in development much earlier than the appearance of the Type-2 basophils.

Acidophils, Type 1. These are very plentiful and are intermingled more or less homogeneously in the adult with the other cell types, only becoming scanty as the terminal zone is approached. They are oval or elongated, with the nucleus typically at one end of the cell, but their orientation varies in different fish. In most fish the finely granular chromophilic substance is directed towards a blood vessel but in others it is as noticeably directed away. They stain yellow-orange with Alcian Blue-PASorange $G$ and a light yellowish green with Luxol Fast Blue-PAS-orange G. After Herlant's tetrachrome they show a slightly greater affinity for the erythrosin, and therefore stain red.

Acidophils Type 2. These cells are always 
confined to the more posterior part of the distal lobe, though here they are just as numerous as are Type-1 acidophils. They are characterized by a slight affinity for PAS, so that after the Alcian combination they stain a brownish orange and after the Luxol a darker bluish green. After the tetrachrome they show yellow.

These two acidophils are too similar in size, shape, and granulation to be separated on other than histological grounds, and even here very good fixation, as well as careful differentiation, is essential. As a result it is not possible to say whether the two types are both present in the smaller larvae of the present material, although acidophils of some sort are certainly present in the posterior part of the lobe of the $7.5-\mathrm{cm}$ fish. Later they spread forwards and laterally and, in a well fixed specimen of $18 \mathrm{~cm}$, both types show clearly. In the very large $(170 \mathrm{~cm})$ fish the great posterior enlargement of the lobe (Fig. 4) contains both acidophils, indeed almost to the exclusion of basophils.

\section{The Intermediate and Nervous Lobes}

These are most easily treated together as a complex, since the two interdigitate in the adult in a complicated pattern of columns and processes of two very different types of tissue. Ventrally, the intermediate lobe is separated from the distal lobe by the hypophysial cavity in smaller fish, although even here some intermingling of the cells round its edges can be seen. However, in the $135-\mathrm{cm}$ fish, the cavity has become occluded in parts, and much of the boundary is no more than a zone where the cell types are mixed. Dorsally, the intermediate tissue is arranged in irregularly-shaped lobules, usually around cavities of various sizes and shapes. A few of these cavities are in open connection with the hypophysial cavity, but the majority are closed. To their outside the lobules may be in contact with each other or separated by processes of the nervous lobe; in both cases, the lobules are bounded by strong sheets of connective tissue carrying a rich supply of small blood vessels. The great majority of the intermediate cells have scattered gran- ules; these are lightly positive to. PAS and Alcian Blue, more strongly so to Gomori's $\mathrm{AF}$ (Fig. 3), and in general resemble those of amphibians. However there are also present appreciable numbers of another cell type with the striking histological peculiarity of being strongly positive to PAS and to Luxol Fast Blue and not to Alcian Blue. These cells (Fig. 10), noticed first by Dawson (1940) because of their additional affinity for orange $G$, have a dense, finely granular cytoplasm and are scattered throughout the lobe but always close to the connective tissue boundary and hence to the blood vessels. In the $11-\mathrm{cm}$ fish these cells already stain strongly and, as in subsequent early stages, are more numerous in relation to the ordinary intermediatelobe cells than they are in the adult (Fig. 7).

The nervous-lobe tissue consists of the usual fibrous matrix, heavily laden with granules of neurosecretion and with occasional pituicytes, and is elaborately penetrated by long processes composed of ependymal cells, some with and some with out a central cavity (Fig. 10). This arrangement can be better understood from developmental stages; in the adults, however, the central tubules can sometimes be seen to originate from the two lateral enlargements of the posterior end of the infundibulum. To either side the reduction in the content of neurosecretion marks the transition of nervous lobe proper into the infundibular wall, but the latter has some direct attachment to the distal lobe through an extension of the connective tissue sheet and its blood vessels. No structures reminiscent of a saceus vasculosus have been seen. Large PAS-positive cells, containing granules and globules of different sizes, occur sporadically in both glandular and nervous lobes; these are assumed to be some form of blood cell.

In developmental stages, a larva of 3 $\mathrm{cm}$ in length shows the infundibulum with a rounded posterior end lying dorsal to the adenohypophysis; within the latter the hypophysial cavity is fully establisned as a flattened slit, extending almost to the edges of the gland, and the layer of glandular 


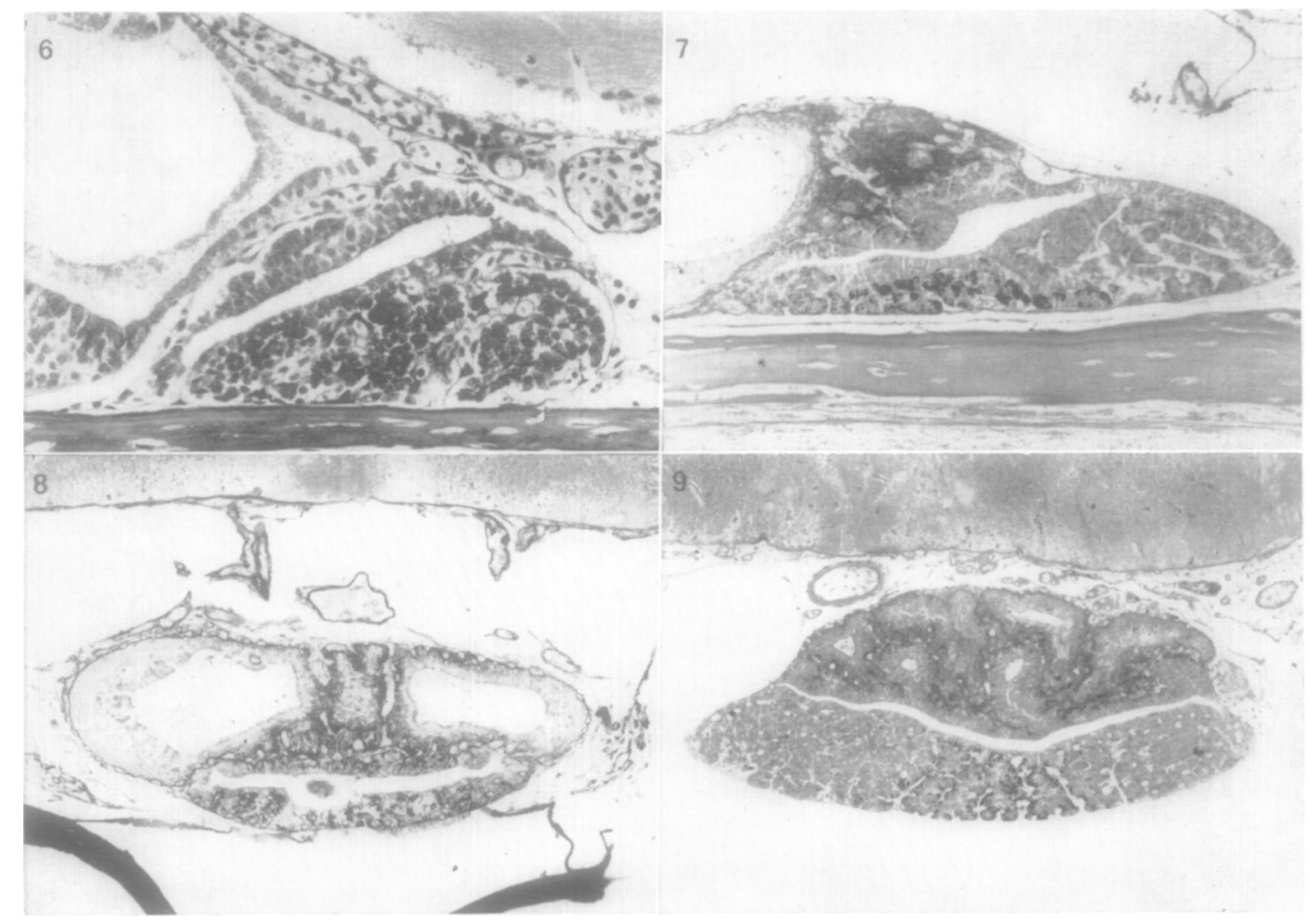

Fig. 6. Parasagittal section of $7.5-\mathrm{cm}$ larva of $P$. aethiopicus to show one infundibular pocket and early adenohypophysis. Mallory. $\times 140$.

FIg. 7. Longitudinal section of $20-\mathrm{cm}$ larva of $P$. aethiopicus; in distal lobe deeply staining (blue) Type-1 basophils are grouped centrally, with lighter-staining (red) Type 3 to front and still lighter (orange) acidophils to rear. Aleian Blue-PAS-orange G. $\times 88$.

FIG. 8. Transverse section of $26-\mathrm{cm}$ larva of $P$. aethiopicus, towards front of gland to show infundibular pockets and early nervous lobe. Alcian Blue-PAS-orange G. $\times 78$.

FIG. 9. Transverse section of 26-cm larva of $P$. aethiopicus through middle of gland to show central Type-1 basophils and lateral acidophils in distal lobe, and early stage of formation of neural-intermediate complex. Alcian Blue-PAS-orange G. $\times 58$.

tissue below the cavity is only slightly thicker than that above. Laler two posteriorly-directed pockets develop from the end of the infundibulum, closely to either side of the midline; in a larva of $7.5 \mathrm{~cm}$, these are well established and the parasagittal section shown (Fig. 6) passes down the middle of one of these pockets. Between the pockets and at their posterior ends the fibrous tissue of the nervous lobe is now beginning to make its appearance with an initial accumulation of neurosecretion, but in the adenohypophysis the intermed atelobe tissue has still, and for some time later, a flat boundary against the nervous lobe above. During further development the amount of fibrous tissue between the infundibular pockels increases (Fig. 8) and the ependymal layer of the pocket walls begins to invade the fibrous tissue as solid strands of cells-at first posteriorly and then from the inner walls of the pocketswhile the outer walls of the latter remain unmodified. Later these strands develop Iumina from their points of origin throughout much of their length, forming a system of tubules communicating with the cavity of the infundibulum. Meanwhile, the intermediate-lobe tissue has begun to grow upwards as irregular columns of cells into the fibrous tissue of the nervous lobe, and to interdigitate with the ependymal processes; 
this is shown in an early stage in the $20-\mathrm{cm}$ fish (Fig. 7) and, in a later stage, in the 26-cm fish (Fig. 9). These columns are at first solid but later they too develop internal cavities, some clearly derived as extensions of the hypophysial cavity, others apparently arising in situ. In the adult the infundibular pockets are reduced to shallow lateral diverticula and the intermingling of nervous and intermediate lobe tissue has become so involved that the simple basic pattern is difficult to recognize.

\section{The Tuberal lobe}

In transverse sections of the earliest larvae, no modification of the anterior tip of the distal lobe has been seen; but in the four larvae from 18 to $26 \mathrm{~cm}$, for which such sections are available, the tip is ex- tending forwards as two short horns lying closely side by side (Hig, 11); these might represent the two lateral lobes from which the tuberal lobe is derived in other forms. The horns cannot be distinguished in longitudinal sections with any certainty, partly because they are only $30-40 \mu$ in length, at least in the present material, and partly because they are composed of the same mixture of Type-3 basophils and chromophobes as is the adjoining terminal zone of the distal lobe.

\section{The Hypothalamo-Hypophysial System}

The preoptic cells, as mentioned by Wingstrand (1956), are quite lightly granulated and in early stages are difficult to identify. The tract leading to the pituitary in the adult is, in addition, noticeably dif-

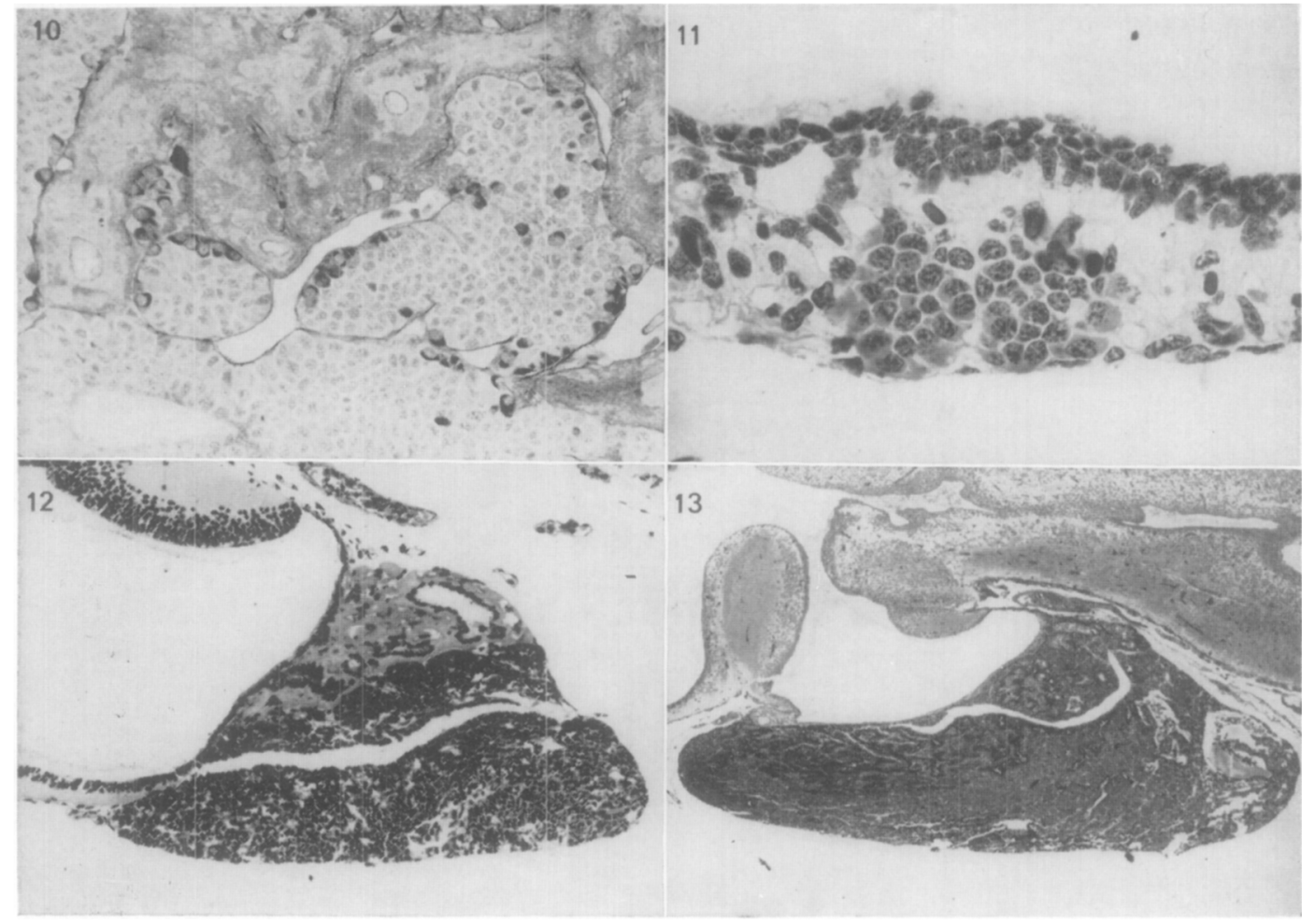

FIg. 10. Part of neural and intermediate lobes of $135 \mathrm{~cm} P$. aethiopicus to show the ordinary and the PAS-positive cells in the intermediate lobe; ependymal cells and tubules and neurosecretion are seen in the nervous lobe. Aleian Blue-PAS-orange G. $\times 140$.

FIa. 11. Transverse section of tuberal lobe region of 18-cm larva of $P$. aethiopicus. Cleveland and Wolfe's trichrome. $\times 350$.

FrG. 12. Longitudinal section of gland of $P$. annectens. PAS-orange G. $\times 70$.

Fig, 13. Longitudinal section of gland of $P$. dolloi. Alcian Blue-PAS-orange G. $\times 20$. 
fuse, but its most distinct portion curves laterally through the infundibular walls to either side and subdivides into an upper and lower part. The lower part supplies the capillaries of the median eminence region and a restricted number of beaded axons pass on into the front of the nervous lobe in the usual way; however the upper and larger part of each main tract continues through the infundibular wall dorsal to the foregoing and leads into the nervous lobe through the whole lateral and dorsal wall of the posterior infundibulum.

\section{Pituitaries of Other Protopterus Species}

The glands of $P$. annectens (Fig. 12) and of $P$. dolloi (Fig. 13), all belonging to adult fish, differ in a number of details from that of $P$. aethiopicus. In both the neural-intermediate complex is very much simpler, recalling rather a devclopmental stage of $P$. aethiopicus (cf. Figs. 7 and 12); in both also the hypophysial cavity forms a continuous slit, without the partial occlusion seen in the larger $P$. aethiopicus, and in $P$. dolloi it shows a tendency to form diverticula somewhat as in Epiceratodus (Griffiths, 1938). In the adenohypophysis of $P$. annectens the cells have very little cytoplasm and shrunken nuclei; this makes it impossible to differentiate with certainty between the basophils of Types 1 and 2, and between the two types of acidophils. In $P$. dolloi only very few and reduced Type-2 acidophils can be seen; the second type of intermediate-lobe cell is also absent in this species, but the amount of material is insufficient to say whether this constitutes an important difference.

\section{DISCUSSION}

The five cell types in the distal lobe of Protopterus recall those of amphibians, both in their histological features and their distribution, although, in the absence of experimental evidence, it must be emphasized that any suggestions about their functions remain tentative.

The Type-1 series of basophils can be equated with the TSH cells of amphibians (van Oordt, 1963, 1966; Kerr, 1965); this is based partly on their early appearance during development and partly on their comparable staining reactions, although in the adult fish these cells are considerably more numerous than they are in amphibians. The Type-2 basophils may represent the FSH series because of their predominance in the adult as compared with their absence in young stages; also, if the rather stronger arguments for the identification of Types 1 and 3 can be accepted, they can be identified by elimination. The Type-3 basophils show the closest resemblance to their suggested amphibian counterparts; their distribution in the anterior part of the lobe, particularly their concentration in the characteristic terminal zone, their shape and staining reactions are all similar to the presumed ICSH cells (Pasteels, 1960; van Oordt, 1961; van Oordt and Lofts, 1963; van Dongen et al., 1966); only in their less precise association with the incoming capillaries do they differ somewhat. Their much earlier appearance during development than the Type-2 basophils is very noticeable.

The two types of acidophils appear comparable to the two seen in amphibians on the basis of their distribution and of their carminophilic or orangeophilic reactions (van Oordt, 1963) as well as the slight affinity of one for PAS (Pasteels and Herlant, 1960-61; Kerr, 1965), although there does appear to be sufficient differcnce in the staining reaction of these cells in different species of amphibians (cf. Copeland, 1943; Pasteels, 1960) to warrant further investigation. On the assumption also that these cells are in fact the sources of the somatotropic and lactotropic hormones it seems possible that their distribution in the large Protopterus gland might allow a differential assay.

A separate tuberal lobe, not to be confused with the terminal zone of the distal Iobe which is sometimes called a zona tuberalis (Harris, 1955), is generally accepted as being absent in lungfish and certainly cannot be distinguished in the adult Protopterus. However the two short horns which have been found developing from the tip of the distal lobe in larvae of a certain range of size do suggest the lateral lobes from which the tuberal lobe originates (see 
de Beer, 1926, for convenient summary); their apparent absence in the adult could be explained by the subdivision of tissue which occurs in this region as the portal system becomes established and which might render a separate tuberal lobe unrecognizable. On the other hand, their small size and very anterior position, as well as the similarity of their cellular composition to the adjacent part of the distal lobe, are all somewhat atypical and more information is required before their homology can be considered established.

The elaborate intermingling of intermediate- and neural-lobe tissue appears to be quite comparable to the condition found in elasmobranchs and primitive actinopterygians; also the pattern of tubules penetrating the nervous tissue from the infundibular cavity is strongly reminiscent of the arrangement seen in the holosteans (Kerr, 1949), Possibly the whole complex represents some very ancient vertebrate organ which loses its importance, and hence its identity, in the land animals. Certainly, in some urodeles (Atwell, 1921), vesicles from the infundibular cavity penetrating the nervous tissue seem to demonstrate the last stages in its disappearance. On the other hand, if a closer comparison with the adenohypophysis of the other fish is attempted then two difficulties appear; the dorsal rather than posterior position of the intermediate lobe in Protopterus, and the subdivision of the glandular component as a whole into two rather than three parts. The first difference may be due merely to a change in the orientation of the gland in Protopterus, since in Epiceratodus (Griffiths, 1938), where the organ lies in a sella turcica below the brain, the intermediate lobe does appear to be more or less posterior. The second difference might be resolved by equating the terminal zone of Protopterus with the proadenohypophysis (rostral pars distalis) of the fish, but this possibility is more difficult to establish.

\section{ACKNOWLEDGMENTS}

For the gift of material we are much indebted to Professor Mare Herlant, Professor W. H. Sawyer, Professor I. Chester Jones, Dr. P. A.
Janssens, Professor M. de Groodt-Lasseel and Dr. Colin Muir. It is also a great pleasure to acknowledge the technical assistance of Mr. J. A. M. Mattheij and Miss Femmy Brands and the skillful photography of Mr. H, van Kooten.

\section{REFERENCES}

Atwell, W. J. (1921). The morphogenesis of the hypophysis in the tailed Amphibia. Anat. Record 22, 373-390.

Dawson, A. B. (1940). The pituitary gland of the African lungfish, Protopterus aethiopicus. Biol. Bull. 78, 275-282.

DE BEer, G. R. (1926). "The Comparative Anatomy, Histology and Development of the Pituitary Body." Biological Monographs and Manuals Series. Oliver and Boyd, London.

Copeland, E. D. (1943). Cytology of the pituitary gland in the developing and adult Tritumis viridescens. J. Morphol. 72, 379-409.

HarRts, G. W. (1955). "Neural Control of the Pituitary Gland." Monograph, Physiological Society, No. 3. Arnold, London.

GaBe, M. (1953). Sur queloues applications de la coloration par la fuchsine-paraldehyde. Rull. Microscop. Appl. 3, 153-162.

Griffiths, M. (1938). Studies on the pituitary body II. Observations on the pituitary in Dipnoi and speculations concerning the evolution of the pituitary. Proc. Linn. Soc. New South Wales 63, 89-94.

HaLmi, N. S. (1952). Differentiation of two types of basophils in the adenohypophysis of the rat and the mouse. Stain Technol. 27, 61-64.

Herlant, M. (1960). Etude critique de deux techniques nouvelles destinées à mettre en évidence les différentes catégories cellulaires présentes dans la glande pituitaire. Bull. Microscop. Appl. 10, 37-44.

KERR, T. (1949). The pituitaries of Amia, Lepidosteus and Acipenser. Proc. Zool. Soc. London 118, 973-983.

KERR, T. (1965). Histology of the distal lobe of the pituitary of Xenopus laevis Daudin. Genl. Comp. Endocrinol. 5, 232-240.

Pasteels, J. L. (1960). Etude expérimentale des différentes catégories d'éléments chromophilies de l'hypophyse adulte de Pleurodeles Wattini, de leur fonction et de leur contrôle par lhypothalamus. Arch. Biol. (Liege) 71, 409-471.

Pasteels, J. L., and Herlant, M. (1960/1). Les différentes catégories de cellules chromophiles de l'hypophyse d'amphibiens. Anat. Anz. 109, 764-767.

van Do:gen, W. J., Jørgminsen, C. B., Larsan, L. O., Lofts, B., vaN OORDT, P. G. W. J. anv 
Rosen kilde, P. (1966). Function and cytology of the normal and autotransplanted pars distalis of the hypophysis of the toad, Bufo bufo (L). Gen. Comp. Endocrinol. 6, 491-518.

vaN OORDt, P. G. W. J. (1961). The gonadotropinproducing and other cell types in the distal lobe of the pituitary of the common frog, Rana temporaria. Genl. Comp. Endocrinol. 1, 364-374. van OоRDt, P. G. W. J. (1963). Cell types in the pars distalis of the amphibian pituitary. Colloq. Intern. Centre Natl. Rech. Sci. 128, 301-313.

vaN OoRdt, P. G. W. J. (1965). Nomenclature of the hormone-producing cells in the adenohypophysis. Genl. Comp. Endocrinol. 5, 131-134. van OоRDt, P. G. W. J. (1966). Changes in the pituitary of the common toad, Bufo bufo, during metamorphosis, and the identification of the thyrotropic cells. Z. Zellforsch. (in the press).

vain OoRdt, P. G. W. J., A.ND Lofts, B. (1963). The effects of high temperature on gonadotrophin secretion in the male common frog (Rana temporaria) during autumn. J. Endocrinol. 27, 137-146.

Wingastand, K. G. (1956). The structure of the pituitary of the African lungfish, Protopterus annectens (Owen). Kgl. Danske Vidensk. Selskab, Medd. Biol. 118, 193-210. 